\title{
A paisagem e o Plano de Urbanização da Praia do Suá, Vitória - ES
}

\author{
ESPINDULA, Lidiane ${ }^{1}$ \\ MENDONÇA, Eneida Maria Souza² \\ 1UFES, Universidade Federal do Espírito Santo, Vitória, Brasil. espindulaprojetos@gmail.com \\ ${ }^{2}$ UFES, Universidade Federal do Espírito Santo, Vitória, Brasil. eneidamendonca@gmail.com
}

\begin{abstract}
Resumo
Este artigo busca identificar a relação do Plano de Urbanização da Praia do Suá, desenvolvido pela Companhia de Melhoramentos e Desenvolvimento Urbano (COMDUSA), com a paisagem. Tal Plano foi apresentado na década de 1970 e culminou, a partir de um aterro, no bairro Enseada do Suá, em Vitória, ES. Esse aterro foi um entre vários realizados na cidade desde 0 final do século XIX, que alteraram a configuração litorânea, afastaram o mar e modificaram hábitos sociais e atividades econômicas. O objetivo geral é apresentar considerações acerca da paisagem e da relação da mesma com o processo de urbanização de Vitória. As fontes se constituíram de documentos originais, estudos técnicos, legislações urbanísticas, fotografias e entrevistas com pessoas chave. Buscou-se analisar 0 discurso apresentado pela COMDUSA com enfoque no tema paisagem, com a apresentação dos usos e dos índices urbanísticos propostos inicialmente para a área e as modificações ao longo dos anos. A paisagem que antes era composta por mar, montanhas e ilhas, passou a ser composta por mar, montanhas, vias, residências e edifícios de múltiplos andares, configurando uma paisagem contemporânea totalmente contraposta à de quarenta anos atrás, predominantemente natural e também, distinta do Plano.
\end{abstract}

Palavras-Chave: Aterro; Paisagem urbana; Produção do espaço urbano; Imagem da cidade.

\begin{abstract}
This article seeks to identify the interaction of the Urban Plan of Praia do Suá, developed by the Companhia de Melhoramentos e Desenvolvimento Urbano (COMDUSA), with the landscape. This Plan was introduced in the 70s and it culminated from a landfill, in the neighborhood Enseada do Suá, in Vitória, ES. This landfill was one of several fulfilled in the city since late IXI century, which changed the coastal setting, away from the sea and modified social habits and economic activities. The main objective is to present consideration about the landscape and it is interaction with the urbanization process of Vitória. The sources were original documents, technical studies, urban planning legislation, photographs and interviews with specific people. It was sought to analyze the speech presented by COMDUSA focusing on landscape theme, with the presentation of the uses and urban indices initially proposed for the area and the change over the years. The landscape was previously composed of sea, mountains and islands, is now composed of sea, mountains, roads, residence and buildings multistory, setting a contemporary landscape totally opposed to forty years ago, predominantly natural and also, distinct from the Plan.
\end{abstract}

Key-words: Landfill; Urban landscape; Production of urban space; City image. 


\section{Introdução}

A partir da segunda metade do século $X X$, o crescimento urbano das grandes cidades brasileiras tem apresentado mudanças significativas na paisagem, principalmente devido aos impactos do processo de ocupação e à dinâmica imobiliária que, muitas vezes, se contrapõem à valorização dos referenciais paisagísticos.

Tais possibilidades de mudanças se baseiam em Santos (2008), quando afirma que:

A paisagem não é dada para todo o sempre, é objeto de mudança. É um resultado de adições e subtrações sucessivas. É uma espécie de marca da história do trabalho, das técnicas. (...) suscetível a mudanças irregulares ao longo do tempo, a paisagem é um conjunto de formas heterogêneas, de idades diferentes, pedaços de tempos históricos representativos das diversas maneiras de produzir as coisas, de construir o espaço (SANTOS, 2008, p.74 e 75).

Vitória, capital do Espírito Santo, está situada no sudeste do Brasil. O mar e o relevo montanhoso possuem papel significativo na paisagem da cidade e compõem um cenário representativo da região, contribuindo na localização e na vida dos habitantes. A cidade foi fundada em 1551, por colonos portugueses que tinham como objetivo a implantação de um novo núcleo urbano na capitania hereditária do Espírito Santo, cuja origem da ocupação remete a 1535 , na então Vila do Espírito Santo, atual Vila Velha. Dentro dos objetivos de ocupação dos colonos, a configuração e a localização da ilha de Vitória eram atrativas, uma vez que proporcionavam estratégias de proteção a ataques (DERENZI, 1995).

Os relatos históricos acerca da chegada e da ocupação inicial de Vitória indicam uma atenção em relação a determinados elementos da paisagem, entre eles o mar. Pesquisas realizadas por Mendonça (2006) descrevem relatos dos percursos feitos pelos viajantes estrangeiros que adentraram a ilha de Vitória pela baía em direção ao porto, no século XIX. Auguste de Saint-Hilaire foi um importante viajante que escreveu livros sobre os costumes e paisagens brasileiros e em 1818 identificou a relação que a ilha de Vitória tinha com o mar e com os morros. Os relatos ressaltam o entusiasmo ao vislumbrar a paisagem de Vitória e do seu entorno (MENDONÇA, 2006).

Em contraponto às características marcantes e de beleza da paisagem de Vitória, que demonstram a imagem da cidade ao longo do século XIX, observa-se que no mesmo período não havia infraestrutura no território, principalmente relacionada à salubridade. Isso indica que vista de perto, a paisagem de Vitória, como de muitas cidades do Brasil à época, estava negativamente comprometida, resultado das condições de saneamento (MENDONÇA, 2006).

Outra questão recorrente era a pequena faixa de terra firme originalmente existente na ilha. $\mathrm{O}$ desenvolvimento da cidade de Vitória se deu basicamente em torno do porto fundado na base do Maciço Central, correspondente ao centro atual da cidade e conhecido como Cidade Alta. Grande parte do território da capital era composta por áreas alagáveis de mangues e brejos.

A partir das características apontadas, fez-se crer, ao longo dos anos, na necessidade de uma expansão territorial devido ao crescimento econômico e populacional e a necessidade de melhorias na infraestrutura da cidade. Consequentemente, diversos aterros foram realizados ocupando as áreas alagáveis e trechos da baía de Vitória.

Segundo Mendonça (2006), o desígnio de manter a cidade como sede política exigiu drásticas alterações da paisagem original. Uma diversidade de justificativas foi formulada para os aterros realizados na cidade e vale ressaltar que algumas estavam relacionadas à criação de paisagens cênicas. Essa justificativa também foi apontada pela Companhia de Melhoramentos e Desenvolvimento Urbano (COMDUSA) para o aterro da atual Enseada do Suá que se deu a partir do Plano de Urbanização da Praia do Suá.

Uma vez que a paisagem está diretamente relacionada à herança e à memória coletiva, é importante estudar a preservação da mesma diante do processo de urbanização. Nesse contexto 
este artigo trata de parte dos resultados obtidos em pesquisa de mestrado que buscou identificar as perdas, os ganhos e as permanências na paisagem do bairro Enseada do Suá.

O objetivo geral - a partir da pesquisa de documentos originais, estudos técnicos, legislações urbanísticas, fotografias e entrevistas com pessoas chave - é apresentar considerações acerca da paisagem e da relação da mesma com o processo de urbanização de Vitória, com um olhar voltado para o bairro Enseada do Suá e identificar a relação do Plano de Urbanização da Praia do Suá com a paisagem. Dessa maneira, buscou-se analisar o discurso apresentado pela COMDUSA com enfoque no tema paisagem, com a apresentação dos usos e dos índices urbanísticos propostos inicialmente para a área e as modificações ao longo dos anos.

\section{Paisagem: breve conceituação}

A paisagem está associada ao processo de percepção das relações que se dão com o espaço e o tempo, entre o homem e o ambiente.

A noção de paisagem está presente na memória do ser humano antes mesmo da elaboração do seu conceito, na observação do meio. Os registros se encontram nas artes que retratam elementos dessa paisagem, como animais, montanhas, rios, entre outros. A história aponta para uma análise da paisagem desde as pinturas rupestres, passando pela antiguidade e no decorrer da Idade Média. A partir do Renascimento, então, diversos conceitos foram propostos.

Cauquelin (2003) indica que a concepção de paisagem dada na modernidade era inexistente entre os gregos, dado como "grau zero". Segundo a autora, a concepção do termo se deu no período do Renascimento, entre os séculos XIII e XVII:

A transformação da pura ideia da natureza, do grau zero da paisagem, em visualidade, inaugurando o que seria a paisagem moderna, ocorre a partir do Renascimento. (...) O receio à grande natureza e o conhecimento do homem restrito à sua circunvizinhança, presentes nos períodos primitivo e medieval, dão lu- gar, no Renascimento, aos desbravamentos dos territórios, e à ampliação da esfera do conhecimento científico. As transformações ocorridas entre os séculos XV e XVIII no sistema produtivo e no pensamento científico estabeleceram uma nova percepção do mundo e, sobretudo, inauguraram uma nova forma de apreensão da paisagem (CAUQUELIN, 2003, p. 25).

Com o passar dos séculos, o tema paisagem passou a ser bastante discutido e estudado por diversos autores. Completamente relacionado com a história e com a cultura da sociedade, o termo, que pode abranger paisagem natural ou construída, representa um papel social importante e está relacionado aos marcos paisagísticos, como montes e rochedos, ilhas, pontes, edificações, entre outros. Esses elementos estão também relacionados com o tempo como suporte da memória dos habitantes de uma cidade (LYNCH, 1997).

É por meio da percepção dos elementos naturais e construídos da paisagem da cidade, de suas particularidades e especificidades, que $o$ ser humano cria suas referências, imagens e identidade locais, construindo a memória coletiva de um povo. Por meio desses elementos o homem se localiza, se orienta e se identifica no espaço urbano (KLUG, 2009).

Os conceitos e as concepções sobre o tema são bastante amplos e variados, discutidos interdisciplinarmente por geógrafos, historiadores, arquitetos, urbanistas, entre outros. Segundo Cosgrove e Jackson (2007), a paisagem possui variedades de fenômenos a serem explorados:

O conceito de paisagem é, ele próprio, um modo especial de compor, estruturar e dar significado a um mundo externo, cuja história tem que ser entendida em relação à apropriação material da terra. (...) Se a paisagem passa a ser considerada uma imagem cultural, um meio pictórico de representar tudo o que circunda o ser humano, então pode ser estudada por meio de vários meios e superfícies (...) (COSGROVE e JACKSON, 2007, p. 23). 
Aziz Ab'Sáber (2003) relaciona o termo paisagem com herança e chama a atenção para a utilização não predatória dessa. $\mathrm{O}$ autor diz que a paisagem é uma herança em todo o sentido da palavra, "herança de processos fisiográficos e biológicos e patrimônio coletivo dos povos que historicamente as herdaram como território de atuação de suas comunidades" (AB'SÁBER, 2003, p. 9).

Segundo Ferreira (1988) e diversos dicionários, tudo aquilo que é visto, o que a visão alcança, é a paisagem. Essa pode ser definida como o domínio do visível, aquilo que a vista abarca. Geralmente, a paisagem é definida por cenários belos que são representados por pinturas $\mathrm{e}$ fotografias, porém também está relacionada a cenários ditos não tão belos, tornando o conceito da mesma ainda mais amplo.

Contudo, a paisagem não é formada apenas pelo olhar, mas também por cores, movimentos, odores, sons, etc., ou seja, sua percepção pode ser complementada por meio de outros sentidos, como auditivo, por meio da percepção dos sons de determinada região, como pássaros, cachoeiras, carros, caminhões, aviões, entre outros. Dessa maneira, é possível compreender Corrêa (2007) quando afirma que a paisagem urbana "permite múltiplas leituras a partir de diversos contextos histórico-culturais, envolvendo diferenças sociais, poder, crenças e valores" (CORRÊA, 2007, p. 179).

Enquanto a paisagem é composta de formas construídas em momentos distintos, o espaço é o resultado entre tais formas e a sociedade. As heranças, antes referidas, também são definidas por Santos (1997) como as rugosidades do espaço, que são aquelas marcas do tempo, porções de trabalho incorporadas à paisagem que permanecem na atualidade. Com relação ao valor do espaço, Santos (1997) afirma que:

[...] o espaço é um sistema de valores, que se transforma rapidamente. O espaço, uno e múltiplo, por suas diversas parcelas, e a partir do seu uso, é um conjunto de mercadorias, cujo valor individual é função do valor que a sociedade, num dado momento, atribui a cada pe- daço de matéria, isto é, cada fração da paisagem (SANTOS, 1997, p. 83).

O espaço se dá pelo acúmulo de trabalho humano nele realizado. É síntese entre paisagem e sociedade. Por sua vez, paisagem não é o mesmo que espaço, embora esses termos sejam muitas vezes utilizados com o mesmo sentido. $O$ autor diferencia paisagem e espaço afirmando que "a paisagem é o conjunto de forma que, num dado momento, exprime as lembranças que representam as sucessivas relações localizadas entre o homem e a natureza. O espaço são essas formas mais a vida que as anima" (SANTOS, 1997, p. 79). O autor complementa:

A paisagem não tem nada de fixo, de imóvel. Cada vez que a sociedade passa por um processo de mudança, a economia, as relações sociais e políticas também mudam, em ritmos e intensidades variados. A mesma coisa acontece em relação ao espaço e a paisagem que se transformam para se adaptar às novas necessidades da sociedade (SANTOS, 1997, p. 79).

\section{O Plano de Urbanização da Praia do Suá}

Como mencionado, o aterro da região da atual Enseada do Suá foi realizado na década de 1970, a partir da elaboração do Plano de Urbanização da Praia do Suá desenvolvido pela COMDUSA, uma empresa vinculada ao Governo do Estado do Espírito Santo, estabelecida a partir de um convênio assinado em 1967 entre as prefeituras dos municípios pertencentes à Grande Vitória para a criação do Plano Integrado da Grande Vitória - COPI, com o objetivo de estabelecer uma política de plano físico territorial para o Espírito Santo.

A década de 1970 se inicia sob o domínio da Ditadura Militar implantada na década anterior, aportada na burocracia, na tecnocracia e no milagre econômico. O planejamento e a elaboração do Plano de Urbanização da Praia do Suá ocorreram no período da Ditadura, quando militares assumiram o governo do Brasil entre os anos de 1964 e 1985. 
O período em questão foi marcado pelo planejamento urbano. Por um viés tecnocrático houve a exigência de elaboração de Planos Diretores com modelos padronizados e compatíveis com a realidade brasileira, com destaque para a racionalização dos custos de urbanização, tendo como objetivo maior eficiência econômica. A partir de extensos diagnósticos, levantamentos de dados quantitativos e a proliferação de índices para medir as necessidades e as qualidades urbanas, o período ficou marcado pela "síndrome do planejamento" (SOUZA, 2004).

No desenvolvimento urbano, o regime militar promoveu um ciclo de luta pela reforma urbana direcionado por arquitetos progressistas (BASSUL et al, 2005, apud MARICATO, 2017). Os Planos Diretores e demais medidas de planejamento territorial naquele período eram instrumentos de soluções de problemas e de resultados no âmbito do desenvolvimento nacional com o intuito de implantar e consolidar políticas públicas para a sociedade brasileira, tanto nacional, quanto regional e local (SANT'ANA et al, 2010). Ferrari Júnior (2004) complementa que:

As metodologias e proposições usadas pelo planejamento urbano modernista foram baseadas em critérios de racionalidade e de caráter exclusivamente técnico, não tendo nenhuma forma de participação da sociedade civil nas discussões de propostas para a cidade, ficando o espaço urbano submetido a normas e padrões que propiciassem, segundo vários autores de cunho marxista, a reprodução da força do capital, conforme os anseios dos atores responsáveis pela "máquina de crescimento urbano" (FERRARI JÚNIOR, 2004, p. 16).

O período histórico-político mencionado refletiu na estrutura funcional do planejamento urbano em diversas cidades brasileiras, inclusive Vitória. Segundo Jolindo Martins Filho - arquiteto responsável pelo primeiro projeto desenvolvido para a região da atual Enseada do Suá - "o aterro na Praia do Suá foi forçadamente realizado, uma imposição feita pelo Departamento de Portos e Vias Navegáveis (DNPVN) para proteger o canal de acesso ao Porto". Ele complementa que "o que era decidido pelo Governo Federal na época, no auge da Ditadura no Bra- sil, não era passível de discussão e não era uma prática a transparência nas informações das decisões políticas à população" (MARTINS FILHO, 2013, s/p).

Múltiplos objetivos e justificativas para o projeto na região foram apresentados pelo governo por meio da COMDUSA, entre eles: a criação de áreas para ocupação residencial; a urbanização da região do Suá; evitar o assoreamento do canal de acesso ao porto; a criação de uma extensa praia e avenida litorânea para uso da coletividade geral; e a "possibilidade de criação de novas atividade comerciais de prestação de serviços na região, deslocando-se do confuso e congestionado Centro de Vitória" (COMDUSA, 1972, s/p).

Martins Filho também explica que a Praia do Suá, por força do assoreamento trazido pelas correntes marítimas, era uma região fétida, pois em períodos de maré baixa brotava um lodo preto, com carcaças de peixe, devido às colônias de pesca existentes que geravam forte odor, sendo necessário também, segundo ele, um aterro para sanear a área.

Demétrio Tedesco, 74 anos, um dos primeiros moradores da Enseada do Suá, também relacionou o aterro ao assoreamento do canal existente na época. Segundo ele, o aterro se deu com o aproveitamento da areia que eles precisavam retirar para rebaixar a profundidade do canal e permitir o atracamento de navios com maior calado, que hoje já é feito retirando a areia e lançando ao longo do oceano (TEDESCO, 2013).

A relação da liberação do canal com a criação de novas áreas de ocupação e urbanização foi também relatada por Kleber Frizzera, arquiteto e professor da Universidade Federal do Espírito Santo. Segundo ele, o aterro era inevitável do ponto de vista físico, uma vez que a região estava completamente degradada pelo assoreamento e, devido à ocupação consolidada da Praia do Canto e dos demais bairros vizinhos, foi preciso aterrar a área na busca de novas áreas de ocupação (FRIZZERA, 2013). 
No texto apresentado, a COMDUSA (1972) informou que, devido ao crescente incremento demográfico verificado principalmente a partir da segunda metade do século $X X$, inexistiam novas áreas destinadas à ocupação por residências em Vitória, pois na época, $40 \%$ de sua área eram cobertas por montanhas. Segundo o Plano, a falta de área em Vitória era considerada um fator impeditivo de desenvolvimento. A partir dos dados apresentados, a empresa justificou a criação de novas áreas na cidade, entre elas a região da Enseada do Suá, também com a intenção de facilitar o trânsito.

Complementarmente, a COMDUSA justificou o aterro em relação à situação administrativocultural da cidade na época, informando que, por ser a capital do Estado, Vitória apresentava uma aglomeração de porte médio, uma vez que empregava uma parcela respeitável da população ativa e que, com a instalação da Universidade Federal do Espírito Santo esse valor tenderia a se ampliar. Além disso, a existência do porto, do sistema de transporte ferroviário e da presença das rodovias BR-101 e BR-262 faziam da cidade um dos principais eixos de transporte de mercadorias do estado. As atividades industriais também atravessavam um processo de evolução. A implantação de um complexo siderúrgico na região com a possibilidade de diversificação de produção da Companhia Vale do Rio Doce era crescente.

Segundo a COMDUSA (1972), a solução era um aterro para a criação de novas áreas para ocupação residencial, a urbanização de novas regiões com possibilidade de áreas para atividades comerciais e de prestação de serviços (transferindo do Centro da cidade) e a criação de uma extensa praia e avenida litorânea para uso da população.

Todas as declarações apresentadas pela Companhia faziam crer na necessidade do aterro que modificou a paisagem da região e das vizinhas. Os registros aéreos apresentados nas Figuras 1 e 2 demonstram a área antes e após o aterro. O projeto fez ligação com afloramentos rochosos contidos em ilhas, como a llha do Boi, a llha do Sururu, a llha do Papagaio e a llha do Bode, e compreendeu também as regiões adja- centes da Praia do Suá, Praia de Santa Helena, Praia do Canto e Praia Comprida.

O Plano de Urbanização aponta diversas vezes sobre a relação do projeto com as ilhas mencionadas. O texto apresentado pela COMDUSA (1972) apresenta a integração das ilhas no território do aterro como um aspecto de valorização paisagística, quando afirma que essa integração busca valorizar os aspectos paisagísticos resultantes dos conjuntos de ilhas do Sururu, do Bode e do Boi, interligando-as. O texto defende a maior parte das duas primeiras ilhas como reservas biológicas. Tal fato confere à zona 0 "usufruto de fator extrínseco efetivo de valorização imobiliária e características ambientais excelentes" (COMDUSA, 1972, s/p).

No entanto, entende-se que o discurso de valorização apresentado pela COMDUSA é questionável. De fato, as ilhas foram interligadas ao território, porém somente interliga-las não garantiu a valorização dos aspectos paisagísticos relativos às mesmas, uma vez que após o aterro deixaram de ser configuradas como ilhas, como demonstrado na Figura 2.

Apesar da constante menção acerca da preocupação com a valorização da paisagem na região, não foram encontrados estudos das características paisagísticas à época e, Martins Filho ao ser questionado a respeito esclarece que as intenções do projeto estavam totalmente relacionadas ao sistema viário e pouco preocupadas com os elementos da paisagem existentes e que, ao se distanciar do projeto, não houve tempo hábil para o desenvolvimento de estudos específicos (MARTINS FILHO, 2013).

A Figura 1 demarca, em vermelho, a presença de um enrocamento (ou quebra-mar) que permitia, segundo Martins Filho, navegar entre a llha do Boi e as llhas do Sururu e do Bode, dando acesso ao Centro de Vitória. Tedesco (2013) afirma o mesmo e segundo ele, no entorno das ilhas mencionadas, pequenas embarcações de pescadores passavam em direção ao late Clube e, posteriormente, para o alto mar.

Figura 1: Imagem aérea da região antes do aterro. 1970. 


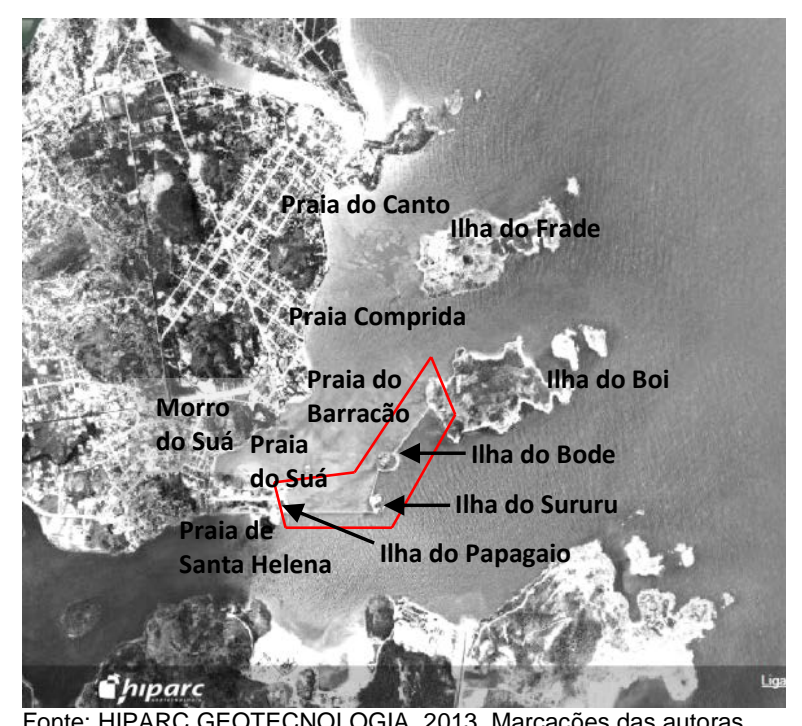

Figura 2: Imagem aérea da região após o aterro. 1978.

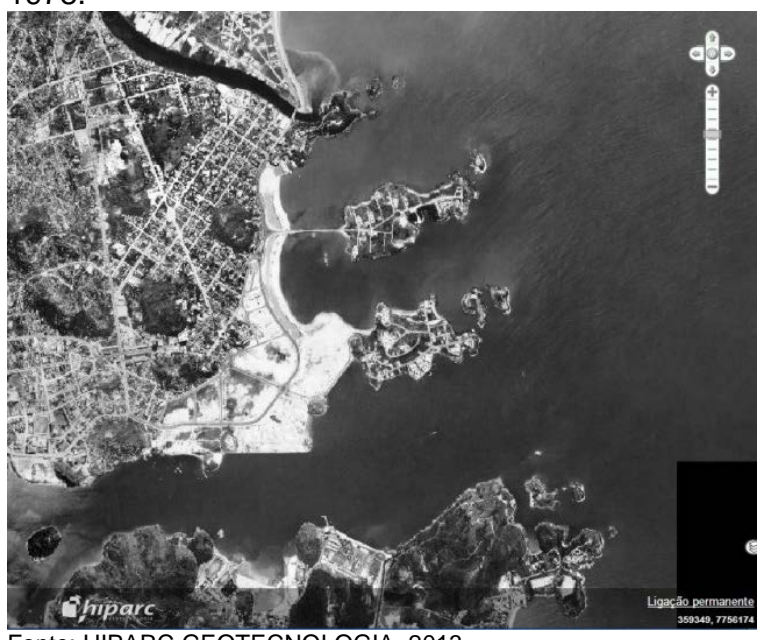

Fonte: HIPARC GEOTECNOLOGIA, 2013.

Dessa maneira, é possível perceber como o aterro configurou uma nova paisagem e como novas configurações espaciais surgiram, alterando o desenho litorâneo, afastando o mar e modificando hábitos sociais e atividades econômicas.

As Figuras 1 e 3 também apontam para algumas praias antes existentes na região que, segundo entrevistas realizadas, guardavam relação social, econômica, cultural e até sentimental com os habitantes. Tais praias deixaram de existir após o aterro, potencializando-se como uma grande transformação na paisagem préexistente. Em entrevistas, diversos moradores e arquitetos que acompanharam o processo de aterro da região, se recordaram das praias que foram substituídas por novas.
Figura 3: Praia do Suá, 1950.

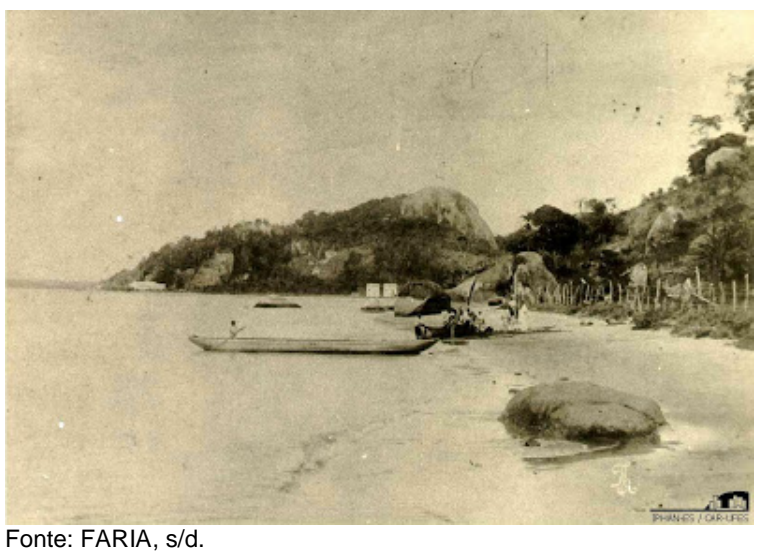

Apesar do aterro realizado, que se configurou como um elemento impactante na estrutura física da região e, principalmente do modo de vida anteriormente existente, a presença do mar e os elementos rochosos do bairro e das regiões circundantes à cidade ainda constituem elementos básicos na definição da paisagem, atuando fortemente em sua identificação e orientação. Porém, vale ressaltar que as praias naturais existentes na região: Praia do Suá, de Santa Helena, do Barracão e Praia Comprida foram substituídas por praias artificiais, criadas a partir do aterro, como a Praia da Curva da Jurema e a Praia do late Clube.

Relacionadas ao mar e às praias antes existentes, a COMDUSA (1972) apresenta um item no Plano de Urbanização referente à destinação de áreas verdes oceânicas para a região. Tal proposta, segundo a Companhia, foi baseada no projeto do Parque do Flamengo, no Rio de Janeiro, e previa atender toda a região da Praia do Suá e Praia do Canto, preenchendo a ausência de área de lazer para a população.

[...] a formação de cerca de dois quilômetros de praia oceânica na região do projeto, o parque de vegetação com áreas de reunião sociocultural é outro fator positivo do empreendimento e o conjunto de melhorias que dele advirão, sob todos os aspectos, representa efetivo passo na elevação do padrão de urbanização da região metropolitana de Vitória (COMDUSA, 1972, s/p).

A COMDUSA complementa apontando para a criação de um "centro cultural-esportivo que 
consagraria em definitivo toda a orla marítima da região do projeto como área de entretenimento e esporte, completando a vocação estabelecida pela existência do late Clube na outra extremidade" (COMDUSA, 1972, s/p). Além desses, diversos outros usos foram apresentados pela COMDUSA, como demonstrado a seguir.

\subsection{Proposta inicial de uso e ocupação do solo}

Antes mesmo do início das obras do aterro um projeto de urbanização foi confiado a Martins Filho pela COMDUSA. Porém, segundo ele, o Plano de Urbanização e o Memorial Descritivo do projeto apresentados e aprovados pela Prefeitura, que servem como base para este estudo, apresentam características diferentes das que propôs originalmente.

De acordo com entrevista com Martins Filho concedida em 2003 a José Francisco Bernardino Freitas (FREITAS e OLIVEIRA, 2009), em função de interesse por parte do empresariado na época, foram feitas alterações no projeto pela própria COMDUSA, sem o consentimento do autor. O mesmo complementou, em entrevista concedida posteriormente (MARTINS FILHO, 2013) que as modificações foram decorrentes do afastamento do mesmo da elaboração da proposta de urbanização, antes mesmo da conclusão das obras, bem como da pressão imobiliária sobre o território.

O projeto original desenvolvido por Martins Filho não foi localizado e o presente estudo apresenta a proposta do Plano de Urbanização, desenvolvida pela COMDUSA em 1972. Segundo a Companhia, o projeto foi concebido sob a vigência do Código Municipal de Vitória de 1954 (Lei $n^{\circ} 351$ ), que foi fundamental nas decisões projetuais e informa que:

[...] por uma razão feliz a coordenação do referido Plano de Desenvolvimento coube à própria COMDUSA que terá assim mais facilidade em dirigir suas decisões rotineiras de ação voltada para a orientação imprimida pelos projetistas do crescimento ordenado da Grande Vitória (COMDUSA, 1972, s/p).
O Código previa para áreas destinadas a uso residencial, taxa de ocupação variando de $60 \%$ a $70 \%$, afastamento frontal de 3 (três) metros e laterais de 1,5 (um e meio) metros e gabarito de 8 (oito) metros. Apesar disso, a COMDUSA utiliza medidas menores, como apresentado na Tabela 1, com afastamento frontal de 6 (seis) metros e laterais de 2,5 (dois e meio) metros, com taxa de ocupação de $60 \%$ e gabarito de até 4 (quatro) pavimentos (FREITAS e OLIVEIRA, 2009).

O Plano justifica os valores em um discurso acerca da valorização dos aspectos paisagísticos do bairro quando apresenta os índices demonstrados, a partir dos maiores afastamentos propostos e do limite do gabarito em até quatro pavimentos. O Plano também indica a valorização da população no projeto com atenção às suas necessidades quando afirma que:

O projeto da llha do Suá enfatiza a valorização do indivíduo na urbe, segundo os princípios de estabelecimento de usos da terra prédeterminados, de projeções do comportamento do crescimento da aglomeração, harmonicamente às necessidades de habitar, trabaIhar, circular e recrear (COMDUSA, 1972, s/p).

Tabela 1: Índices urbanísticos definidos pelo Código Municipal de Vitória (Lei n³51/54) e pelo Plano de Urbanização da COMDUSA em 1972.

\begin{tabular}{|c|c|c|c|}
\hline TO & GM & AF & $\mathrm{AL}$ \\
\hline \multicolumn{4}{|c|}{ Código Municipal de Vitória (Lei nº 351/54) } \\
\hline $60 \%$ & 8pav. & $3 m$ & $1,5 \mathrm{~m}$ \\
\hline \multicolumn{4}{|c|}{ Plano de Urbanização da Praia do Suá (COMDUSA) } \\
\hline $60 \%$ & 4pav. & $6 \mathrm{~m}$ & $2,5 \mathrm{~m}$ \\
\hline
\end{tabular}

Dessa maneira, o Plano, além dos índices urbanísticos, apresenta os usos previstos para a área e a relação deles com a parcela do território, apresentadas na Tabela 2 e na Figura 4. Também apresenta quatro superquadras destinadas ao uso residencial em condomínio, todas dotadas de equipamentos de lazer, áreas verdes e estacionamentos e ainda $10 \%$ de área destinada a atividades associadas ao ensino. Para esse uso são estabelecidos novos índices, como demonstrado na Tabela 3. 
Tabela 2: Usos previstos do Plano de Urbanização da Praia do Suá, COMDUSA, 1972.

Uso Residencial Unifamiliar

(RU) e Residencial em

$40 \%$

Condomínio (RC)

Uso de Comércio e Serviço

(CS)

$11 \%$

Sistema Viário

Áreas de lazer

Áreas privativas da colônia

de pesca

Ministério do Exército e da

$49 \%$

Marinha

Centro cultural-esportivo

(praia)

Usos não definidos

Fonte: Freitas e Oliveira, 2009.

Tabela 3: Índices urbanísticos definidos pelo Plano de Urbanização da COMDUSA em 1972, para a os usos residenciais em condomínio.

\begin{tabular}{|c|c|c|c|}
\hline TO & GM & AF & $A L$ \\
\hline \multicolumn{4}{|c|}{$\begin{array}{l}\text { Plano de Urbanização da Praia do Suá (COMDUSA). } \\
\text { Índices urbanísticos para RC. }\end{array}$} \\
\hline 40 a $50 \%$ & 3pav. & $6 m$ & $2,5 \mathrm{~m}$ \\
\hline
\end{tabular}

Comparando as Tabelas 3 e 4, percebe-se que para a Zona Residencial há uma diminuição quanto às possibilidades de ocupações nos lotes e quanto às alturas das edificações, porém os afastamentos são mantidos.

O mapa apresentado pela COMDUSA (Figura 4) também indica a localização do uso definido como Residencial Unifamiliar (RU), com 24 (vinte e quatro) quadras e 321 (trezentos e vinte e um lotes), localizados próximo ao mar e às "llhas" do Bode, Sururu e Boi. Para este setor, o Plano define novos índices, distintos das zonas, mantendo os afastamentos definidos para as RC's, porém diminuindo o gabarito para dois pavimentos e elevando a taxa de ocupação, de acordo com a definida para as demais zonas (Tabela 4).

Tabela 4: Índices urbanísticos definidos pelo Plano de Urbanização da COMDUSA em 1972, para a os usos residenciais unifamiliares.

\begin{tabular}{lccc}
\hline TO & GM & AF & AL \\
\hline Plano de Urbanização da Praia do Suá (COMDUSA). \\
Índices urbanísticos para RU. \\
\hline $60 \%$ & 2pav. & $6 \mathrm{~m}$ & $2,5 \mathrm{~m}$ \\
\hline \multicolumn{4}{l}{ Fonte: COMDUSA, 1972.}
\end{tabular}

TO: Taxa de Ocupação/ GM: Gabarito Máximo/ AF: Afastamento Frontal/ AL: Afastamento Lateral

Figura 4: Proposta de urbanização da área de aterro da Enseada do Suá.

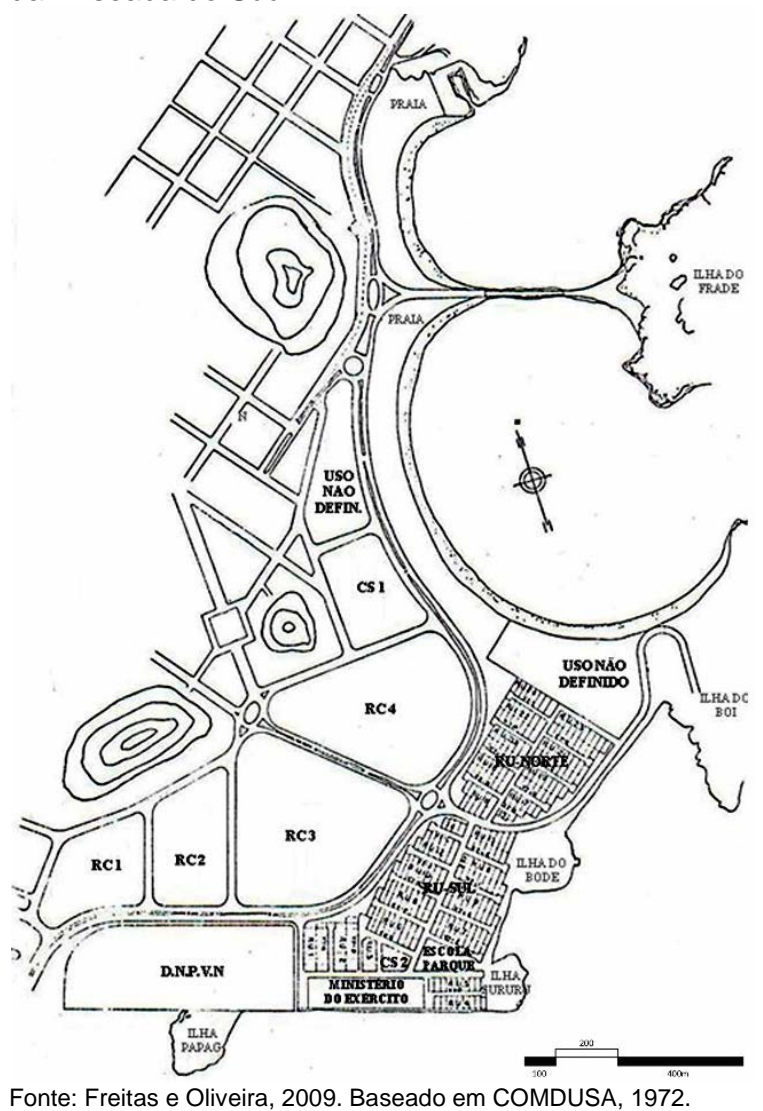

A área residencial unifamiliar (RU) foi dividida em dois setores e em 24 quadras. Foram previstos afastamentos laterais mínimos de 2,5 metros e frontal de 6,0 metros e gabarito máximo de dois pavimentos com ocupação máxima de $60 \%$ do lote. Previu-se também área destinada a escola-parque, como para a área residencial em condomínios (RC) (COMDUSA, 1972).

As áreas destinadas aos usos de comércio e serviço foram divididas em duas glebas, uma delas próximo à nova praia originada do aterro. De acordo com o Plano, as novas áreas de comércio e serviço buscariam atender à população da região e dos bairros vizinhos, apontando áreas de uso indefinido como possibilidade de expansão também para esses usos.

O Plano também indica uma faixa de terra para separar o eixo viário da praia, com largura em torno de cem metros, destinada ao lazer. Para a área, foi previsto a instalação de equipamentos culturais e esportivos, mencionados anterior- 
mente, como uma das justificativas de aterro apresentadas pela COMDUSA.

Analisando a proposta inicial de uso e ocupação apresentada pela COMDUSA, observa-se a pressão do mercado imobiliário mesmo antes da execução do aterro. Apesar disso, o discurso do Plano estava voltado para a valorização da paisagem a partir do controle dos índices urbanísticos demonstrados.

\subsection{Alterações no Plano aprovadas pela Prefeitura Municipal de Vitória}

O plano urbanístico desenvolvido inicialmente não foi executado como tal, tendo sido realizadas alterações no mesmo ano por parte da COMDUSA e aprovadas pela Prefeitura por meio de um Memorial Descritivo. O Memorial encontra-se sem data, mas Freitas e Oliveira (2009) localizaram o projeto aprovado na Prefeitura com a indicação em 1975.

Mesmo diante das alterações, o Memorial mantém o discurso do Plano de Urbanização quanto à concepção do projeto, no que diz respeito aos conceitos adotados de acordo com as escolas de urbanismo, buscando dar valor ao indivíduo, atendendo às suas necessidades básicas: habitar, trabalhar, circular e recrear.

As alterações apresentadas na nova proposta da COMDUSA foram realizadas devido à pressão do setor imobiliário que interveio no desenho original, nos usos propostos para a região, na tipologia construtiva e na concepção das áreas destinadas a espaços verdes, com imposições que refletiram não somente na morfologia do local, quanto no sistema viário e no tamanho dos lotes e das quadras.

A Figura 5 apresenta as mesmas superquadras para uso residencial em condomínio (RC's) e, para a gleba com uso não definido próximo à Ilha do Boi, foi estabelecido o uso de comércio e serviço, como informado no Plano como zona de expansão desse uso. Outra gleba de uso antes indefinido se uniu ao uso denominado $\mathrm{RU}$ Norte, modificando sua localização e incluindo trecho antes definido como área de comércio e serviço (CS1). Um novo trecho ainda foi definido como Área Remanescente (AR1).
Figura 5: Planta de locação; urbanização da Enseada do Suá.

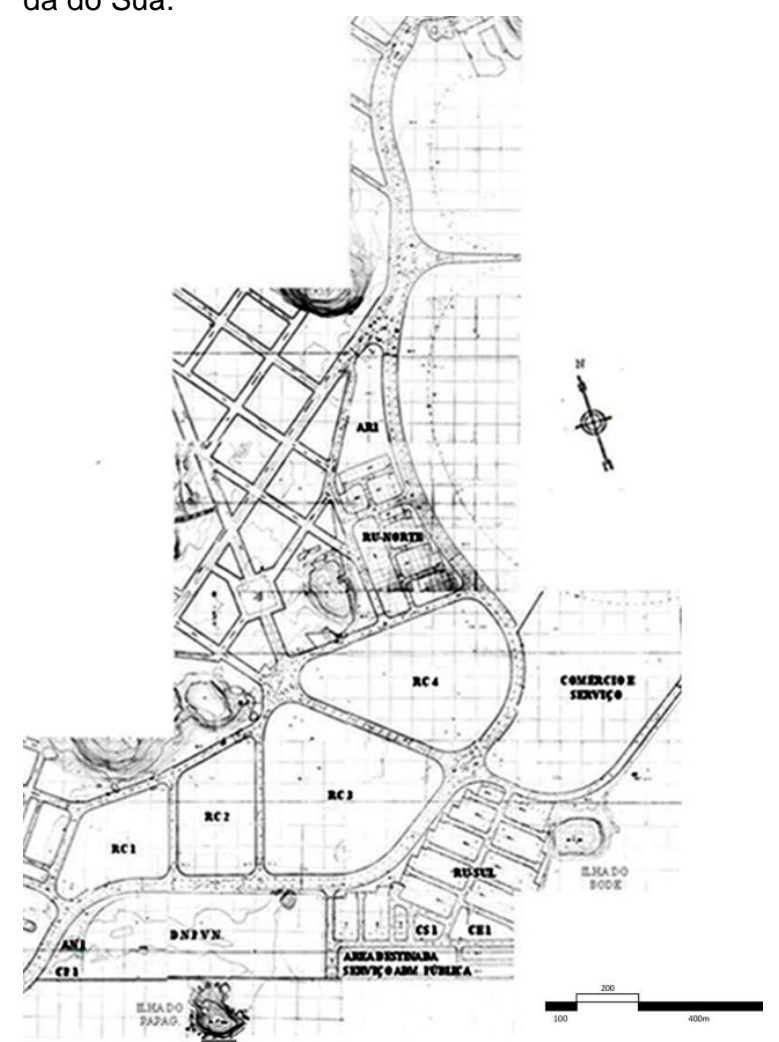

Fonte: Freitas e Oliveira, 2009. Secretaria de Desenvolvimento da Cidade - SEDEC da Prefeitura Municipal de Vitória - PMV: Mosaico composto por pranchas de 1972 com aprovação do projeto de 1975.

Observa-se, então, uma ampliação das áreas destinadas a comércio e serviço e uma redução da área residencial, consequentemente das áreas destinadas aos espaços livres, grande perda identificada na paisagem natural. Apesar das modificações do projeto, é possível identificar que o planejamento para a urbanização da região da Praia do Suá partiu de um projeto ordenado. Foram estabelecidas alternativas de criação de espaço urbano de acordo com constatações de viabilidade técnico-operacional para a execução de aterros por meio de metodologias atualizadas, "procurando desenvolver áreas de integração dos novos ambientes com a conturbação que Vitória apresentava" (COMDUSA, 1972, s/p).

Segundo Freitas e Oliveira (2009), durante o período de aprovação do Memorial, Termos Aditivos (1975, 1976, 1982 e 1985) foram propostos pela COMDUSA, objetivando outras alterações no projeto relacionadas aos usos e aos índices urbanísticos que resultaram na configuração atual da Enseada do Suá. Alterações dos usos e dos índices urbanísticos a partir dos 
Planos Diretores Urbanos de Vitória de 1994, 1996 e 2006 também colaboraram para a situação atual.

Atualmente, a Enseada do Suá possui área de $1,25 \mathrm{~km}^{2}, 1,34 \%$ da área total de Vitória (IBGE, 2010). Sua localização no município é privilegiada, devido à proximidade com o mar e por possuir ligação com o município vizinho de Vila Velha por meio da Ponte Deputado Darcy Castello de Mendonça ("Terceira Ponte"). Faz parte de uma área de centro de negócios e de valorização imobiliária, juntamente com os bairros vizinhos de Praia do Canto, Bento Ferreira, Praia de Santa Helena, Santa Lúcia e devido à sua relativa proximidade com o Centro da cidade.

Na região há diversos equipamentos extensivos à cidade, com uma variedade de usos, como órgãos públicos, comércios de grande porte, serviços, em meio à área habitacional e de lazer (atual Parque Linear. Figura 6).

O parque em questão, conhecido como Praça dos Namorados, Praça dos Desejos e Praça da Ciência, também compreende as Praias do Canto e da Jurema (praias artificiais criadas após o aterro) e foi idealizado pela COMDUSA baseado no Aterro do Flamengo, como mencionado anteriormente.

Figura 6: Parque Linear, Enseada do Suá, 2011.

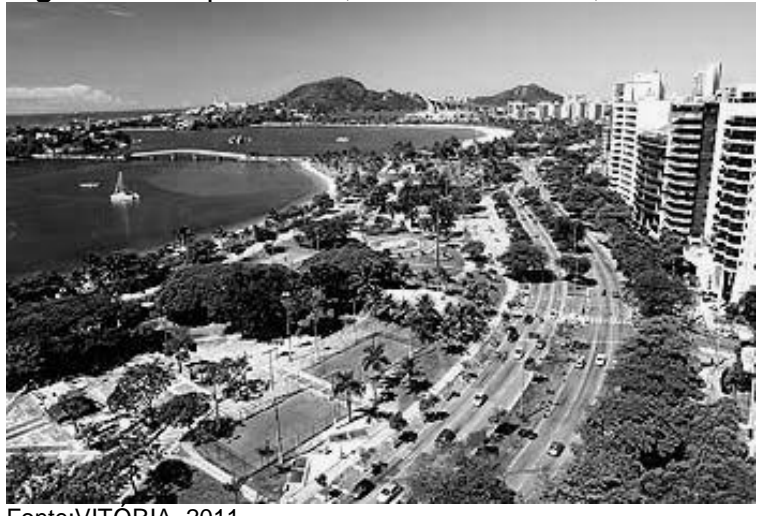

Fonte:VITÓRIA, 2011

O Parque do Flamengo (Figura 7) também é um parque linear construído sobre aterro na cidade do Rio de Janeiro, construído na década de 1960. A proposta foi de criação de um "pulmão" natural para a cidade, também como solução para saneamento ambiental e de lazer ativo, além de propostas para o sistema viário.
Figura 7: Parque do Flamengo, Rio de Janeiro, s/d.

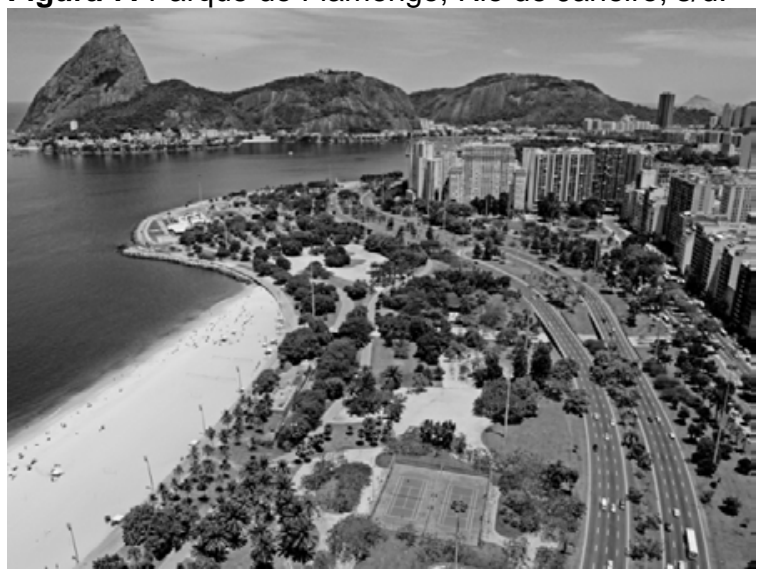

Fonte: MACEDO e SAKATA, 2002.

O projeto também aborda o aspecto da valorização paisagística a partir de duas ideias- chave: a de se criar uma nova paisagem e a da democratização dos espaços públicos (CAIXETA, 2002). A autora complementa que:

No parque do Aterro, a natureza e a técnica aparecem como um binômio perfeito, ambas possuem coerência interna e imunidade a fatores externos que possam perturbar sua lógica. Como espaço social e educativo, o parque articula signos ambivalentes que representam um sonho de ordem social (CAIXETA, 2002, p.66).

A concepção morfológica de ambos os parques se assemelha por sua linearidade e pelo desenho que contornam as duas baías. Tanto o Parque do Flamengo quanto o Parque Linear da Enseada do Suá são limitados por vias e mar, além de mares de morros e edificações de grande porte.

O interior dos parques é composto por variados equipamentos de lazer ativo, como quadras, pistas de caminhada, playgrounds, entre outros, além do aspecto paisagístico, visível na estrutura verde existente, além de quiosques e restaurantes.

\section{Conclusão}

$\mathrm{O}$ aterro que culminou na criação do bairro Enseada do Suá se deu a partir do Plano de Urbanização da Praia do Suá, desenvolvido pela COMDUSA em 1970. O Plano apresentou um discurso voltado para a valorização da paisagem, a partir do controle dos índices urbanísti- 
cos demonstrados e para a valorização do indivíduo na urbe, buscando atender às necessidades do mesmo.

Apesar do constante discurso encontrado nos textos do Plano de Urbanização quanto à preocupação com a paisagem, não foram encontrados estudos específicos quanto à manutenção $\mathrm{e}$ preservação da paisagem existente à época. Tal preocupação é justificada pela definição dos usos do solo e dos índices urbanísticos, porém os mesmos foram modificados antes mesmo da conclusão do aterro e novas propostas foram estabelecidas e aprovadas pela Prefeitura, diante da pressão do mercado imobiliário. Observou-se nas mudanças uma redução de áreas destinadas aos espaços livres e verdes, configurando uma perda para a paisagem natural da região.

Apesar das alterações, o projeto aprovado e executado deu um tratamento à orla, como previsto inicialmente no Plano, com a criação do Parque Linear, com a destinação de uma área verde litorânea com praias e usos destinados ao lazer, à cultura, ao esporte, com espaços arborizados e com possibilidades de contemplação da paisagem, apresentando-se como um dos principais ganhos identificados a partir do aterro.

Percebe-se, após o estudo das alterações ao longo dos anos, uma predominância de usos residenciais e de comércios e serviços, como previsto inicialmente no projeto desenvolvido pela COMDUSA, porém localizados em diferentes áreas e construídos com índices distintos do projeto inicial.

A paisagem que antes era composta por mar, montanhas e ilhas, distintamente, passou a ser composta por mar, montanhas, vias, residências e edifícios de múltiplos andares, configurando uma paisagem contemporânea totalmente contraposta à de cerca de quarenta anos atrás, predominantemente natural. Tais alterações, como defendido por diversos autores, são naturais e resultado das ações do homem ao longo dos anos não só da Enseada do Suá, mas em todo o município de Vitória.
É importante que pesquisas acerca das transformações paisagísticas do bairro sejam continuadas, uma vez que é de suma importância o estudo da preservação da paisagem diante do processo de crescimento urbano da cidade como forma de preservação e de suporte da memória coletiva dos habitantes.

\section{Agradecimentos}

A CAPES pela concessão da bolsa de pesquisa. Capítulo de dissertação de mestrado.

\section{Referências}

AB'SABER, Aziz. Os domínios de natureza no Brasil: potencialidades paisagísticas. São Paulo: Ateliê Editorial, 2003.

BRASIL. INSTITUTO BRASILEIRO DE GEOGRAFIA E ESTATÍSTICA. Dados censo 2010. Disponível em http://www.ibge.gov.br/home/. Acesso em: 07 out. 2016.

CAIXETA, Eline Maria Moura Pereira. Uma arquitetura para a cidade: a obra de Affonso Eduardo Reidy. ARQTEXTO (UFRGS), Porto Alegre, v. 2, p. 58-67, 2002.

CAUQUELIN, A. Paisagem, retórica e patrimônio. RUA. Revista de Arquitetura e Urbanismo. Salvador, v.6, 2003.

COMDUSA. Plano de Urbanização da Praia do Suá, Estudo de Viabilidade. Vitória, 1972.

CORRÊA, R. L. A geografia cultural e o urbano. In: CORREAA, R. L.; ROSENDAHL, Z. Introdução à geografia cultural. 2. Ed. Rio de Janeiro: Bertrand, 2007.p. 167-186.

COSGROVE D; JACKSON, P. Novos rumos da geografia cultural. In: CORREAA, Roberto Lobato; ROSENDAHL, Zeny (Org). Introdução à geografia cultural. 2. Rio de Janeiro: Bertrand, 2007.

DERENZI, Luiz Serafim. Biografia de uma Ilha. 2 ed. Vitória: PMV, Secretaria Municipal de Cultura e Turismo, 1995.

FARIA, W. de. Nova Cidade ou Water Front em Vitória (ES): Um projeto dentro da Lei Municipal e fora da aprovação judiciária. Disponível em: <http://deolhonailha-

vix.blogspot.com.br/2011/09/nova-cidade-emvitoria-es-um-projeto.html>. Acesso em: 11 out. 2016. 
FERRARI JÚNIOR, José Carlos. Limites e Potencialidade do Planejamento Urbano: uma discussão sobre os pilares e aspectos recentes da organização espacial das cidades brasileiras. Revista Estudos Geográficos, Rio Claro, 2(1):15-28, junho, 2004 (ISS 1678-698x).

FERREIRA, A. B. de H.. Dicionário Aurélio Básico da Língua Portuguesa. Rio de Janeiro: Nova Fronteira, 1988.

FREITAS, José Francisco Bernardino; OLIVEIRA, Aline Nogueira. Aterro e proposta de ocupação para a Enseada do Suá: 1970 - 2009. Pesquisa (Iniciação Científica) - Núcleo de Estudos de Arquitetura e Urbanismo - NAU, Universidade Federal do Espírito Santo, Vitória, 2009.

FRIZZERA, Kleber Perini. A paisagem da Enseada do Suá. 2013. Entrevista concedida a Lidiane Espindula, Vitória, 24 out. 2013.

HIPARC GEOTECNOLOGIA. Veracidade: linha do tempo 1970 - 2007. Disponível em: http://www.veracidade.com.br/. Acesso em: 19 ago. 2013.

KLUG, L. B. Vitória: sítio físico e paisagem. Vitória: EDUFES, 2009.

LYNCH. K. A imagem da cidade. São Paulo: Martins Fontes, 1997.

MACEDO, S. S.; SAKATA, F. G. Parques Urbanos no Brasil. São Paulo: Editora Edusp, 2002 207p.

MARICATO, Ermínia. O impasse da política urbana no Brasil. Petrópolis: Vozes, 2017.

MARTINS FILHO, Jolindo. A paisagem da Enseada do Suá. Entrevista concedida a Lidiane Espindula, Vitória, 17 outubro 2013.

MENDONÇA, Eneida Maria Souza. Mudança na paisagem de Vitória (ES) pelo projeto de Saturnino de Brito - argumentos metodológicos para análise e construção da paisagem In: IX Seminário de História da Cidade e do Urbanismo. Anais... FAU-USP / EESC-USP / Mackenzie / PUC-Campinas. São Paulo. 2006. p.1-15.

SANT'ANA, Jayça Lima; FAVA, Gustavo de Souza; BUENO, Laura Machado de Mello. Planejamento, gestão e participação: a política urbana e as disputas pelo território. Scripta Nova. Revista electrónica de geografía y ciencias sociales. Universidad de Barcelona. ISSN: 1138-9788. Vol. XIV, núm. 331 (8), 2010.

SANTOS, M. A urbanização brasileira. 5 edição. São Paulo: EDUSP: 2008.
SOUZA, Maria Adélia Aparecida de Souza. O II PND e a Política Urbana Brasileira: Uma Contradição Evidente, In O Processo de Urbanização no Brasil. São Paulo: EDUSP, 2004.

TEDESCO, Demétrio. A paisagem da Enseada do Suá. Entrevista concedida a Lidiane Espindula, Vitória, 22 de outubro de 2013.

VITÓRIA, PREFEITURA MUNICIPAL. Praça do Papa oferece visão panorâmica da baía de Vitória, 2011. Disponível em: $<$ http://www.vitoria.es.gov.br/turismo.php?pagin a=pracadopapa>. Acesso em: 11 out. 2013.

VITÓRIA. Lei no 351, de 24 de abril de 1954. Código Municipal de Vitória. Secretaria Municipal de Planejamento/PMV, Vitória, 1954. 